\title{
Factors affecting students' intentions to undertake online learning: an empirical study in Vietnam
}

\author{
Greeni Maheshwari ${ }^{1}$ (D)
}

Received: 4 December 2020 / Accepted: 7 February 2021 / Published online: 4 March 2021

(C) The Author(s), under exclusive licence to Springer Science+Business Media, LLC part of Springer Nature 2021

\begin{abstract}
Educational institutions worldwide had to shift the teaching delivery mode from face to face to online teaching during COVID-19. Most of the universities in Vietnam were based on face to face learning until the sudden outbreak of COVID-19. This research study was conducted with 145 respondents and Structural Equation Model (SEM) was used for data analysis. The participants were undergraduate and post-graduate students in public and private universities who studied online during the pandemic in Vietnam. The purpose of this study was to understand what factors have an impact on students' intentions to study online. The results show that institutional support and perceived enjoyment (satisfaction) affects the students' intentions to study the course online in the future. Perceived enjoyment (PE) affects the online learning intentions (OLI) and PE is affected by ICT infrastructure and internet speed and access. Hence, this research adds new research variable defined as extrinsic factors (ICT infrastructure and access to the internet), which indirectly influences students' intentions to learn online. Given the increased use of smart phones with this generation, it is advisable to integrate mobile technology in online learning and QR codes can be one of the ways to integrate that in the course materials. It is further recommended that to increase the perceived enjoyment of the students with the online learning, the lecturers might be encouraged to use videos, audios and instant messaging to contact and provide the feedback to the students. It is important for universities to prepare for any such future crisis. This study results will provide a useful insight to design the online courses effectively by considering all the factors impacting students' intention and satisfaction.
\end{abstract}

Keywords COVID-19·TAM · Online learning · Students intentions · Perceived enjoyment - Vietnam

Greeni Maheshwari

greeni.maheshwari@rmit.edu.vn

1 Economics and Finance Department, RMIT University, Ho Chi Minh City, Vietnam 


\section{Introduction}

\subsection{The concept of online learning}

There are different learning environments such as face to face learning, distance learning, learning and online learning where the learners can learn. Online learning and e-learning are mostly used interchangeably, but there is a difference in these two terms. E-learning is about accessing the web-based technological tools that might be used in the classroom or outside the class (Maheshwari and Thomas 2017; Nichols 2003). Online learning is about describing the learning "wholly online" where the learners learn outside the classroom and is considered similar to distance learning but using online platforms (Oblinger et al. 2005). Online delivery mode can offer efficient and convenient ways to achieve the learning outcomes for students learning online (Junco et al. 2013). The effectiveness of online learning might be impacted by many factors such as technological aspects, user-friendly online platform, class activities and assessments (Wijekumar et al. 2006; Shuey 2002). As the outbreak of COVID-19 has forced many institutions to switch their teaching mode to online teaching instead of face-to-face teaching, it is vital for the institutions to understand what factors might impact the satisfaction of students and further their intention to learn the courses online in the future. The institutions have to be well prepared for any uncertainties happening in the future. Hence, the main purpose of this research is to identify what factors impact the students' online learning intentions in the future.

\subsubsection{Online learning scenario in Vietnam}

The first outbreak of COVID-19 in Vietnam happened in late January 2020, and since then the Government made a very assertive decision and closed all the educational institutions. After that, schools and the universities were asked to roll out their teaching to online mode (Pollack et al. 2020). It was not an easy situation for teachers and students. For many students and the teachers, this was the first time ever being exposed to online learning. Due to the pandemic, a very high percentage of students in Vietnam had to study online which included $58.8 \%$ students from undergraduate or vocational programs and $39.1 \%$ of students from post-graduate program (B and Company 2020). The survey conducted in Vietnam found that only one-third of the students had any experience with online learning before COVID-19 outbreak (B and Company 2020). The three main streaming platforms used for online learning in Vietnam were Zoom, Microsoft Teams and Google Meet. Zoom was not much preferred by Ministry of Education and Training (MOET) due to security issues (B and Company 2020). Before COVID-19, the students in Vietnam were using e-learning platforms to learn English or soft skill courses, and e-learning model was getting recognized with those courses in Vietnam since a decade but learning the regular courses in school or university is new in Vietnam (Vietnam Economic Times 2018). For many years, online learning has been proposed but did not receive much enthusiasm from universities, academics and students in Vietnam (Vietnam Economic Times 2018). Only during the outbreak, the universities in Vietnam had no choice but to work with online learning plans, and this pandemic has provided a great opportunity for universities to review the ICT infrastructure, the training required for the staff to deliver the content online and many more (Nguyen and Pham 2020). 


\subsection{Online learning: Not an option but a necessity}

Many parts of the world were or are still under lockdown due to the outbreak of global pandemic COVID-19, and the effect of a pandemic is seen on all the industries, including the educational sector. All the schools and universities around the world are impacted during the pandemic, and many educational institutions had to continue delivering the courses online as that is the only option in the current situation. Due to this, the institutions had to make the overnight shift from face-to-face learning to elearning amidst this chaos. As the move to change from traditional to online teaching pedagogical approaches was very quick, and hence the digitization of content was not fully incorporated by the universities. Hence, during this difficult and uncertain time, it has become necessary for every educational institution to maintain their teaching standards along with maintaining the students' enrollments. It will be hard for any universities in the current time to resist this change from traditional teaching to online teaching else they will not be able to survive in this sector. Considering this, it is quite important for educational institutions to understand the factors that play a vital role in attracting the students and motivating them to continue taking the courses online in the future. The outbreak of various viruses like SARS, MERS-CoV, Ebola and many more has been hitting the world for many decades (A Train Education 2020). To prepare for the uncertainties, the universities in Vietnam and worldwide have to be better equipped and might need to initiate this online learning and embed them in their curriculum permanently for the future.

\section{Literature review}

\subsection{Factors affecting online learning}

Virtual classroom has a very different environment compared to regular face-to-face classroom sessions. The online courses' design and delivery have a huge impact on students' satisfaction, learning and retention in the online courses (Irani 2005). The researchers have identified that three kinds of interaction are crucial with online learning; learner-learner interaction, learner-content interaction and learner-instruction interaction (Moore 1989). The survey done by BEAN on undergraduate and postgraduate students in Vietnam who studied online during pandemic, indicated that the internet's stability and speed was considered the top factor impacting students' learning experience with online learning (B and company 2020). The next three critical factors which affected students' online learning experience were: comfortable and quiet learning environment, teachers' support and ease of using the learning platform. There can be various other factors that might impact learners' learning experience and intention to study online in the future as discussed next.

\subsection{The technology acceptance model (TAM)}

The first model that included technology acceptance based on psychological factors was technology acceptance model (TAM) which discussed how users accept and use the technology (Davis et al. 1992). According to the TAM model, the two essential 
factors which affect the user's acceptance of technology are Perceived Usefulness (PU) and Perceived Ease of Use (PEU). Further, as per TAM model, the intentions to use technology are influenced by users' acceptance and has direct and indirect effects of perceived usefulness and perceived ease of use (Davis et al. 1992). Perceived enjoyment (PE) is defined as how much the user enjoys using the technology apart from performance consequences (Davis et al. 1989). Perceived Usefulness (PU) is about how much the user thinks that a particular technology will enhance their performance, while Perceived Ease of Use (PEU) is when the person believes that using the technology will be free of efforts (Davis 1989). TAM has been a popular model used in the number of studies to determine the effectiveness of online business education, with several studies using the original framework and some used the extended model based on the respective studies' objective. Liu et al. (2010) used TAM to explore the factors that affect intention to use an online learning wherein they used online course design, user interface design, previous learning experience as an explanatory variables and intention of online learning as a response variable. The study done by Zhang et al. (2008) also used TAM to examine the factors contributing to the learners' acceptance behaviour with web-based learning systems, wherein the predictor used was an intrinsic motivator. Bazelais et al. (2018) in their study used the variables PU, PEU and attitude towards technology to predict intention to use technology. Further review of literature is provided to guide towards the hypothesis development of this study, in the next section of this paper.

\subsection{Objective of the study}

Most of the past studies focused on different areas of online learning, such as the differences in students' performance, their attitudes, and their satisfaction level while studying the courses online and on campus. Some studies focused on the designing the learning activities to make online learning effective. However, very few studies such as the study done by Tung and Chang (2007) have focused on identifying the intention of students to take up the course online, and this study will add more knowledge towards this area in the literature. As discussed earlier, TAM has been used in various studies but the variables chosen to explore the Online Learning Intention (OLI), defined as an intention to continue learning the courses online in the future, were different in those studies (such as intrinsic motivator, online course design, user interface design, previous learning experience, PU, PEU). This current study also uses modified TAM with predictors as extrinsic factors (ICT infrastructure support and internet resources such as speed and internet access), intrinsic factors (PEU and self-efficacy (SE)) and institutional support (IS) (Class learning activities and teachers support). The variables on the extrinsic factor have not been used in any other models to study students' online learning intention to the best of the knowledge. Also, based on the literature search, no studies have been done so far in Vietnam, addressing the factors affecting online learning intention, as very few universities in Vietnam offered online learning till the time they were forced to offer online classes due to COVID-19. This study aims to contribute to the knowledge of growing literature and makes an effort to add new research variable related to extrinsic factors in the existing models. This study examines the influence of intrinsic factors, 
institutional factors, extrinsic factors, PU and PE (measure of satisfaction) to determine students' intentions to study the courses online in the future offerings.

Intrinsic factors are defined as the traits within an individual such as motivation, confidence which are not determined by the external environment (Ayub 2010). In contrast, extrinsic factors are the factors which affects an individual due to external circumstances such as external environment and culture (Ayub 2010). PE and PU are defined in section 2.2. The intrinsic factors in this study include PEU (as defined in section 2.2) and self-efficacy (SE) defined as one's belief in their ability to succeed in given circumstances (Zimmerman 2000). The ICT infrastructure and internet resources are part of extrinsic factors in this study. Several hypotheses discussed in the next section have emerged from the literature review which are framed around the main issue of students' intentions for online learning, and those are addressed in this study. Hence, the results from this study will help the institutions in Vietnam to understand as to how they can design the online courses effectively moving forward which can attract the students towards online learning as now online learning seems to be no more an option, but it has become a necessity.

\section{Hypotheses development}

\subsection{Extrinsic factors, intrinsic factors, and perceived enjoyment}

There are different barriers in proper integration of technology in the online class such as intrinsic factors which includes personal beliefs in using technology, self-efficacy (Brinkerhoff 2006; Teo and Noyes 2011) and extrinsic factors such as available resources (internet access, technical support) (Butler and Sellbom 2002; Shamburg 2004; Teo and Noyes 2011). Lack of Self-efficacy (Self-confidence) and perceived competence have a negative impact on the use of technology and this discourages the teachers, and the students from integrating technology in their teaching and learning (Piper and Yan 2001). Most of the studies focused on teaches' intrinsic sills, but very few studies have focused on students' intrinsic skills. Hence, this study intends to know whether the same results holds true for students as well and what is the relationship of extrinsic and intrinsic factors with perceived enjoyment. Based on these rationales, the following two hypotheses are designed for this study:

$\mathbf{H}_{1}$ : Is there any relationship between Extrinsic factors and Perceived Enjoyment (PE)?

$\mathbf{H}_{2}$ : Is there any relationship between Intrinsic factors (Self-Efficacy (SE) and Perceived Ease of Use (PEU) and Perceived Enjoyment (PE)?

\subsection{Class activities, teachers support and learning satisfaction}

This research study did not collect the data on specific technology used by the students during their online classes, but the study done by Dinh and Nguyen (2020) in Vietnam highlighted the usage of different technology instruments by the university students in Vietnam during online learning in the same time period as this study. The study results 
found that the technology instruments used by students during online learning were desktop, tablet, laptop and mobile phone and out of these, the most frequently used technology instruments were smart phone (80.36\%) and laptop (77.65\%) (Dinh and Nguyen 2020). Although, this current study did not collect the data on the technology used by the students in the online learning but given that the study done by Dinh and Nguyen (2020) has been conducted during the same time in Vietnam, their study results can be replicated here too and it can be assumed that in this study also, the students might have used the mobile phones most frequently, as that is the most convenient way of accessing online sessions. The study done by Simpson and Du (2004) suggested that the experience of learners studying online using any technology is quite different from students learning onsite. The study further suggested that during synchronous online sessions, the participation and class interaction in the course affects the students learning experience (Simpson and Du 2004). During online synchronous sessions, the teachers and the students are expected to be live simultaneously. Most of the online learning in the past was based on asynchronous learning where the learners could access the materials, ask questions to their lecturer and learn at their own pace anytime as per their convenience. However, since the availability of synchronous tools, most of the teachers shifted their teaching using this learning mode to overcome the challenges of asynchronous learning (Hsiao 2012). Hence, all the learning activities during synchronous sessions affect the students' satisfaction with their online learning. Lack of sense of community and feeling of isolation in online class participation with peers and teachers negatively affects the students learning experience as reported by Vonderwell (2003); Woods (2002) in their studies. Further, major of students is also considered as one of the factor affecting online learning. It was found that there is a significant difference between the preferred teaching method for the students in a nonEnglish major as compared to students with an English major (Noora 2008). The girls are found to be more participative and have more confidence to participate in online class than boys as per the study done by Fassinger (1995), indicating the gender significance. In this current study, there are two-third of female participants with the rest are male participants, and most of the students were studying at undergraduate level comprising of $90 \%$ of the sample. Cole et al. (2014) found in their study that there was no significant difference in satisfaction with online learning between undergraduate and post-graduate students, while this result was not similar to the study done by Kuo et al. (2013) who found that there was a significant difference in the satisfaction of students based on the class level. The undergraduate students were less participative as compared to post-graduate students (Kuo et al. 2013). The study by Lim (2001) found that there is a positive relationship between learners' perceived enjoyment and their intention to participate in future online courses. The class activities and course integration in designing the course with appropriate learning activities enhance class participation and play a positive role in learners' intention with online learning (Hung and Jeng 2013; Liu et al. 2010). Given the importance of class participation and teachers support on perceived enjoyment and further the effect of online learning experience on their intention to learn courses online, the below hypotheses are proposed in this study:

$\mathbf{H}_{3}$ : Is there any relationship between Institutional Support (IS) which includes class activities and teachers support and Perceived Enjoyment (PE)? 
$\mathbf{H}_{4}$ : Is there any relationship between Perceived Enjoyment (PE) and online learning intentions (OLI)?

$\mathbf{H}_{5}$ : Is there any relationship between Institutional Support (IS) and online learning intentions (OLI)?

\subsection{Intrinsic factors, perceived usefulness and intentions}

The intrinsic factors of this study are measured by PEU and Self-efficacy (SE) (as defined in section 2.2) and SE is found to be directly related to the students' academic performance in the universities and is a predictor of some measures of success in the university (Gore 2006). For performing better in the assessment, class participation and teachers support are important as this is where students get the opportunity to clarify any doubt they might have during their studies (Galyon et al. 2012). Hence, it might be possible that instead of this indirect effect, class participation and self-efficacy may have a direct impact which will lead to better academic performance. A study suggests that lack of self-efficacy will affect Online Learners' Intention (OLI) (as defined in section 2.2) to study the courses online in the future as they might not feel confident in their skills and abilities (Collins 1999).

It was found that the perceived usefulness has correlation with intentions to use technology by the users (Venkatesh and Morris 2000). Another study result suggests that intrinsic factors such as self-efficacy directly influence learners' intentions to use technology (Mun and Hwang 2003). The perceived usefulness of online learning is considered to have relationship with the intrinsic factors (PEU and SE). Perceived usefulness was based on the questions related to how useful online learning was for the students to stimulate the interest for the course and understand the content better. Hence, perceived usefulness and intrinsic factors might affect the intentions of learners. In recognition of the existence of these relationships, the following hypotheses are planned for this study:

$\mathbf{H}_{\mathbf{6}}$ : Is there any relationship between Intrinsic factors and Perceived Usefulness (PU)?

$\mathbf{H}_{7}$ : Is there any relationship between PU and online learning intentions (OLI)?

The theoretical framework denoting the study hypotheses as presented in Fig. 1 was derived based on the literature discussed above.

\section{Methodology}

\subsection{Survey instrument and data collection}

A survey instrument on intention to study courses online was developed using TAM and by looking at various literature on online learning. The reliability and validity of the survey items were tested in the designed questionnaire. There were several sections in the instrument. The first section was on the demographics of the students. The second section consisted of questions regarding extrinsic factors. The next section was on the 


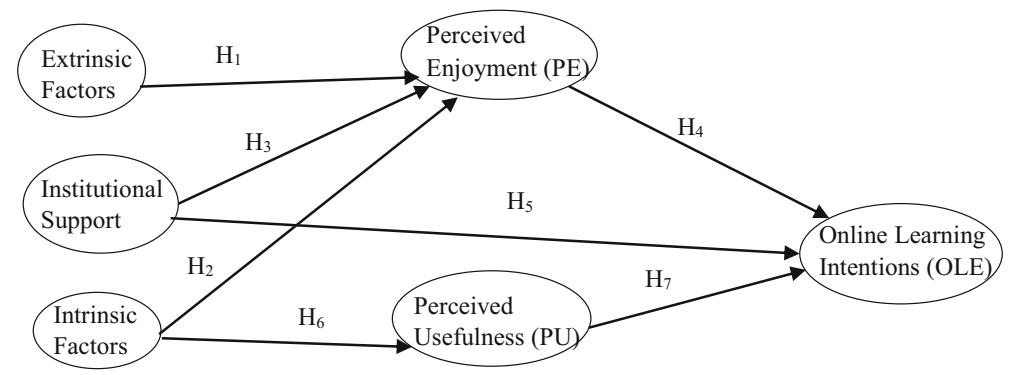

Fig. 1 Theoretical Framework denoting study hypotheses

questions related to institutional support. The fourth section consisted of intrinsic factors. The fifth section was regarding the students' perceived enjoyment and perceived usefulness. Finally, the last section consisted of the questions related to their intention to study the online courses in the future. All the survey questions were designed on 7-point Likert scale ranging from "totally disagree" to "totally agree".

\subsection{Structural Equation Modelling}

Structural Equation modelling is a combination of Exploratory Factor Analysis (EFA) and multiple regression which also helps identify the causal relationship (Ullman et al. 2001). Some of the items of the constructs were adapted from other studies (Eyitayo 2011; Esterhuyse et al. 2016) and hence instead of using EFA, Confirmatory Factor Analysis (CFA) is used in this study to understand whether the data fit into the hypothesized measurement model (Thompson 2004). Factor analysis using varimax rotation was done initially to determine the number of factors which had an eigen value higher than 1. Factor analysis is performed to understand the correlations between different variables and to find the joint observed variables (Akaike 1987). In the factor analysis, only those items with the loading of 0.4 or higher were considered to be large enough to retain and rest with lower item loadings, or cross-loadings were eliminated. Further, based on the factors identified, the six factors were labelled as Extrinsic factors (Infrastructure support and internet resources such as internet availability and speed of the internet), Institutional support (Class activities and teachers support), Intrinsic factors (Perceived ease of use and self-efficacy), Perceived enjoyment (measure of satisfaction) and Online learning intentions. The six identified factors can be seen in an appendix in Table 7 , which explained $76.1 \%$ of the total variation. The Kaiser-Meyer-Olkin (KMO) value was 0.896 (which is sufficiently higher), and the Barlett's test of Sphericity also showed the significant result. Following the factor analysis, the construct in the model included are shown below and in Fig. 2:

- Extrinsic factors (2 items)

- Institutional support (2 items)

- Intrinsic factors (2 items)

- Perceived enjoyment (6 items)

- Perceived usefulness (3 items)

- Online learning intentions (2 items) 


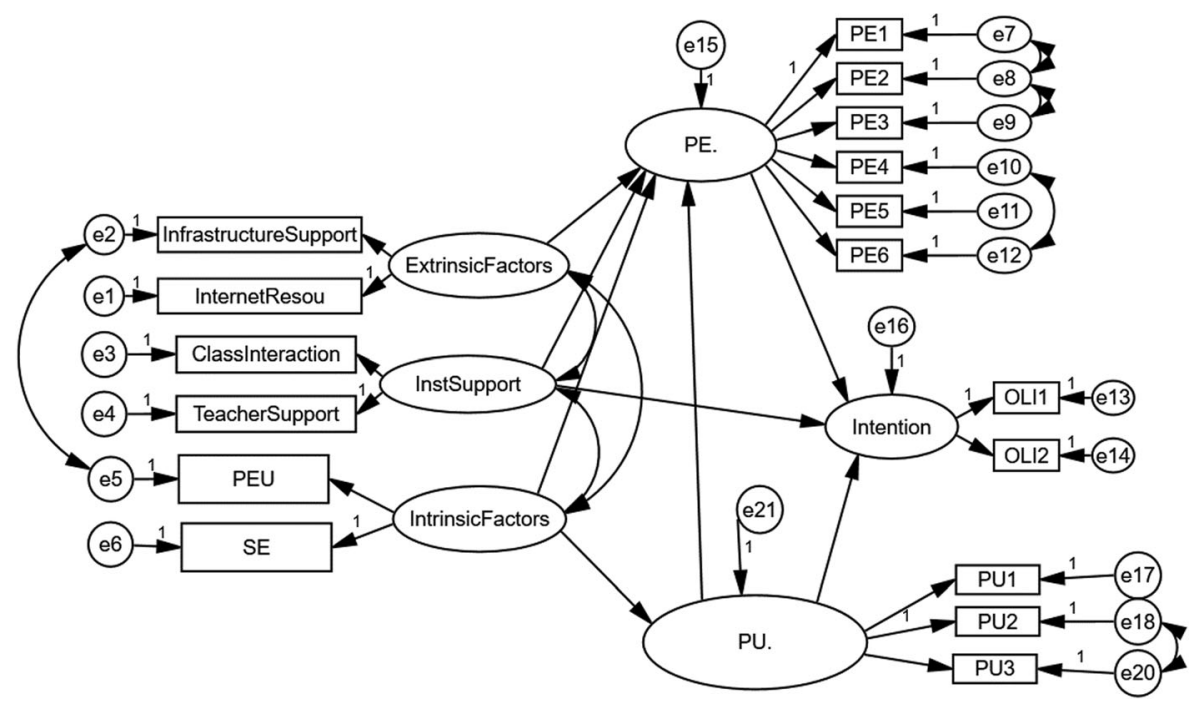

Fig. 2 SEM (CFA) Model

Figure 2 shows the CFA model for this study.

The model fit was tested using various goodness and badness of fit measures. The structural equation model specified the relationship between different constructs considered in the model. The various model fit indices are displayed in Table 1 below.

\section{Results and analysis}

\subsection{Descriptive statistics}

The participants for this study were the students (undergraduate/post-graduate) who studied the courses online during the pandemic in Vietnam. The survey link was posted on the researcher's social networking site and then the snowball sampling method was used to disseminate the survey further. A total of 209 participants did the survey, but only 145 responses could be used due to some

Table 1 Model fit indices

\begin{tabular}{llll}
\hline Index & Value & Acceptable range & Reference \\
\hline Cmin/df & 1.716 & $<3$ & Meydan and Sesen 2015 \\
GFI & 0.88 & $>0.8$ & Doll et al. (1994); Baumgartner and Homburg (1996) \\
AGFI & 0.82 & $>0.8$ & Doll et al. (1994); Baumgartner and Homburg (1996) \\
NFI & 0.92 & $>0.9$ & Hooper et al. 2008 \\
CFI & 0.96 & $>0.9$ & Quintana and Maxwell (1999) \\
RMSEA & 0.071 & $<0.08$ & Hu and Bentler 1999 \\
\hline
\end{tabular}


missing values in the data after data cleaning process. There were $66 \%$ female and $34 \%$ male, $46 \%$ of the students were from private universities and rest $54 \%$ from public universities. Out of these, most of the students $(90.3 \%)$ were undergraduate and the rest were post-graduate students.

Regression was used to diagnose if there are any outliers or multicollinearity or any violations in the assumptions, but no such serious issues were found. Hence, after this, the descriptive analysis was conducted on survey items, as shown in Table 2 below. The standard deviation ranged between -2 to +2 indicating that there was not much deviation from the normal distribution and hence most of the statistical analysis could be applied to the model in this study (Badri et al. 2016).

Table 2 Descriptive measures of the survey items

\begin{tabular}{llc}
\hline Survey items descriptive scores & & \\
\hline Extrinsic Factors & Mean & S.D. \\
Infrastructural Support & 5.29 & 1.21 \\
Internet Resources & 6.11 & 1.06 \\
& & \\
Institutional Support & Mean & S.D. \\
Class Interaction & 5.08 & 1.26 \\
Teachers Support & 5.60 & 1.26 \\
& & \\
Intrinsic Factors & Mean \\
Perceived Easy to Use (PEU) & 5.59 & S.D. \\
Self-Efficacy (SE) & 5.36 & 1.13 \\
& & 1.14 \\
Perceived Enjoyment (PE) & Mean \\
PE1 & 4.83 & \\
PE2 & 5.09 & S.D. \\
PE3 & 5.15 & 1.7 \\
PE4 & 4.83 & 1.590 \\
PE6 & 4.98 & 1.529 \\
PE8 & 4.69 & 1.656 \\
& & 1.781 \\
Online study intentions (OLI) & Mean & 1.742 \\
OLI1 & 4.57 & \\
OLI2 & 4.61 & S.D. \\
Perceived Usefulness (PU) & & 1.98 \\
PU1 & 6.28 & 1.901 \\
PU2 & 6.18 & S.D. \\
PU3 & 5.56 & 1.083 \\
\hline & & 1.194 \\
& & 1.532 \\
\hline
\end{tabular}

* Mean calculation based on the Likert scale of 7 


\subsection{Measurement model validity, reliability, and correlation}

The reliability analysis is done on the six factors using Cronbach's Alpha which ranged from 0.84 to 0.95 (Table 6 in appendix) which exhibited the acceptable level above 0.7 of all the items in the construct (Brown 2002). Convergent validity in AMOS was conducted to validate the items under each construct and Table 7 in appendix shows the output of the convergent validity test and reliability test. Average Variance Extracted (AVE) was greater than 0.5 (Byrne 2013) for each construct which indicated that the items on each construct were convergent (Table 6 in appendix).

Table 3 below represents the correlation between the constructs used in the study. All the bivariate correlations are significant with the highest correlation (0.984) (number in bold in Table 3) between perceived enjoyment and online study intentions. Other correlations are between 0.69 to 0.38 . There are bivariate relationships less than 0.5 between few variables, although all are significant.

\subsection{Hypothesis testing}

The Table 4 below shows the designed hypotheses of this study and the results obtained from SEM analysis.

Based on the theoretical framework, it was expected that perceived enjoyment might act as a mediator between extrinsic factors, institutional factors and intrinsic factors on learners' intentions and show the indirect impact on intentions for online learning. However, the results suggested that online learning satisfaction do have a direct, but there was no indirect effect found on online learning intentions.

This study's first hypothesis was to determine if there was any relationship between extrinsic factors and perceived enjoyment. It was found that there was a relationship between the internet resources and infrastructure on PE. The second hypothesis was to test how the intrinsic factors (perceived easy to use and self-efficacy) can affect PE and no relationship was found between these variables. The third hypothesis was to determine if there was any relationship between institutional support provided and PE. The results indicated a positive relationship between these two variables with a coefficient of 0.941 . The fourth hypothesis intended to test the relationship between PE

Table 3 Correlation between the constructs

\begin{tabular}{lllllll}
\hline & $\begin{array}{l}\text { Extrinsic } \\
\text { Factors }\end{array}$ & $\begin{array}{l}\text { Institutional } \\
\text { Support }\end{array}$ & $\begin{array}{l}\text { Intrinsic } \\
\text { Factors }\end{array}$ & $\begin{array}{l}\text { Perceived } \\
\text { Enjoyment }\end{array}$ & $\begin{array}{l}\text { Perceived } \\
\text { Usefulness }\end{array}$ & $\begin{array}{l}\text { Online Learning } \\
\text { Intentions }\end{array}$ \\
\hline Extrinsic Factors & 1 & & & & & \\
Institutional Support & $.509^{* *}$ & 1 & & & \\
Intrinsic Factors & $.628^{* *}$ & $.688^{* *}$ & 1 & & \\
Perceived Enjoyment & $.404^{* *}$ & $.656^{* *}$ & $.484^{* *}$ & 1 & 1 & \\
Perceived Usefulness & $.651^{* *}$ & $.482^{* *}$ & $.508^{* *}$ & $.466^{* *}$ & 1 \\
Online Learning & $.378^{* *}$ & $.639^{* *}$ & $.464^{* *}$ & $.984^{* *}$ & $.446^{* *}$ & 1 \\
$\quad$ Intentions & & & & & & \\
\hline$* *$ for $p<.01$ & & & & & & \\
\hline
\end{tabular}

$* *$ for $p<.01$ 
Table 4 Coefficients and hypotheses testing results

\begin{tabular}{lllll}
\hline Hypothesis & Path & Standardized Coefficient & $p$ value & Result \\
\hline $\mathrm{H}_{1}$ & Extrinsic Factors $\rightarrow$ PE & -0.456 & $<0.1$ & Supported \\
$\mathrm{H}_{2}$ & Intrinsic Factors $\rightarrow \mathrm{PE}$ & -0.019 & $>0.1$ & Not Supported \\
$\mathrm{H}_{3}$ & Institutional Support $\rightarrow$ PE & 0.941 & $<0.01$ & Supported \\
$\mathrm{H}_{4}$ & PE $\rightarrow$ OLI & 1.066 & $<0.01$ & Supported \\
$\mathrm{H}_{5}$ & Institutional Support $\rightarrow$ OLI & -0.24 & $<0.05$ & Supported \\
$\mathrm{H}_{6}$ & Intrinsic Factors $\rightarrow$ PU & 0.798 & $<0.01$ & Supported \\
$\mathrm{H}_{7}$ & PU $\rightarrow$ OLI & 0.056 & $>0.1$ & Not Supported \\
\hline
\end{tabular}

on OLI and the positive relationship was found between these variables. The fifth hypothesis was to test the impact of institutional support on OLI, and the results suggested that institutional support does have the relationship, but it was found to be negative. The sixth hypothesis was to understand how intrinsic factors might affect the perceived usefulness of technology and the direct effect of intrinsic factors was found on PU. The last hypothesis of this study was not supported, which was about determining any relationship between PU and OLI. The overall coefficient of determination for this entire model was $72 \%$.

\subsection{One-way ANOVA analysis}

One-way analysis of variance was conducted to test the differences between constructs on the demographic variables collected in the study. Various demographic variables included Gender (Male, Female), Age (18-20 years, 21-23 years, 24-26 years), Education level (Undergraduate, post-graduate), Type of school (public, private), Years of using computer (1-3 years, 4-6 years, 7-9 years, 10-12 years and 13 or more years), Average hours spent on the computer (1-10 h, 11-20 h, 21-30 h, 31-40 h and over $40 \mathrm{~h}$ ) and whether a student has a computer (yes, no). Table 5 below shows the results ( $p$-value) of the one-way ANOVA analysis.

Table 5 One-way ANOVA (significance values)

\begin{tabular}{llllllll}
\hline Constructs & Gender & Age & $\begin{array}{l}\text { Education } \\
\text { level }\end{array}$ & $\begin{array}{l}\text { Type } \\
\text { of school }\end{array}$ & $\begin{array}{l}\text { Years } \\
\text { of using } \\
\text { computer }\end{array}$ & $\begin{array}{l}\text { Average } \\
\text { hours spent } \\
\text { on computer }\end{array}$ & $\begin{array}{l}\text { Have personal } \\
\text { computer }\end{array}$ \\
\hline Extrinsic Factors & 0.182 & 0.107 & $\mathbf{0 . 0 0 0 * * *}$ & 0.301 & 0.412 & $\mathbf{0 . 0 1 2} * *$ & 0.712 \\
Institutional Support & 0.521 & 0.108 & $\mathbf{0 . 0 4 0} * *$ & $\mathbf{0 . 0 1 5} *$ & 0.860 & 0.262 & 0.914 \\
Intrinsic Factors & $\mathbf{0 . 0 6 4} *$ & 0.148 & $\mathbf{0 . 0 0 0} * * *$ & 0.314 & 0.276 & 0.636 & 0.997 \\
Perceived Enjoyment & 0.196 & $\mathbf{0 . 0 5 7} *$ & 0.253 & $\mathbf{0 . 0 5 *}$ & 0.897 & 0.174 & 0.512 \\
Online Learning & 0.129 & $\mathbf{0 . 0 0 8} * * *$ & $\mathbf{0 . 0 6 3} *$ & 0.628 & 0.837 & $\mathbf{0 . 0 2 5} * *$ & 0.92 \\
\multicolumn{1}{c}{ Intentions } & & & & & & & 0.643 \\
Perceived Usefulness & 0.760 & 0.724 & 0.106 & 0.205 & 0.507 & $\mathbf{0 . 0 5 7 *}$ \\
\hline
\end{tabular}

$*, * *, * * *$ respectively significant at $10 \%, 5 \%$ and $1 \%$ 
The results indicated that the extrinsic factors were affected by education level and an average number of hours using a computer. The results on difference of means suggested that undergraduate students have higher mean scores (5.8) than post-graduate students with a mean score of 4.8 , which means undergraduate have higher inclination towards extrinsic factors. In terms of years of using a computer, the mean score of support was 6.0 (highest years of using a computer) in comparison to 5.2 (lowest years used). With respect to institutional support, the results showed that education level was significant with higher mean scores for undergraduate students (5.4) than post-graduate students (4.8) and institutional support also had the correlation with the type of university (public/private). Perceived ease of use and self-efficacy (intrinsic factors) was also affected by educational level suggesting that undergraduate students consider technology easy to use (6.0) as compared to post-graduate students (5.3) and selfefficacy was higher as well for undergraduate students as compared to post-graduate students. Further, intrinsic factors were also being affected by gender. The correlation was found between perceived enjoyment with age and educational level. The students who spent more hours on the computer had higher intentions to study with a mean of 5.7 than others with a mean of 4.7. Also, the learning intentions were being affected by age and the educational level. Finally, the students who had the computer considered better usefulness of technology with a mean score of 6.0 compared to those who did not have a computer.

\section{Discussion}

The current study's results provided the model to understand the students' intentions to use online learning in the future. The results showed that the students OLI were influenced by institutional support provided and the perceived enjoyment with the course. The study done by Lee (2010) found that the students' perception on the support and the quality of the course impacted their online intensions and this study found similar results as well. The support provided from the institution in the form of class activities, class interaction and teachers' support played an important role in students decision-making to study the courses online in the future. Institutional support (IS) was found to be an important factor in this study and had the relationship with PE (measure of satisfaction of students) and these results are also in line with the previous studies by Yukselturk and Yildirim (2008); Lee et al. (2011). Further, PE had a positive relationship with the students OLI. From the results, it can be understood that higher the satisfaction of the students with their learning, they might intend to study online in the future.

The perceived enjoyment (PE) had a direct effect on OLI and further PE was inversely affected by extrinsic factors based on this study's results. Hence, even though, the direct effect was not found of extrinsic factors (ICT infrastructure and internet speed and access) on OLI, but the indirect effect was observed on OLI. This result from the study was supported by BEAN survey wherein $71.1 \%$ of the university students in Vietnam mentioned that due to unstable and slow internet connection their online learning was impacted and internet connectivity has to be improved in the future to make the online learning effective (B and Company 2020). The similar survey on high school students suggested that the attendance dropped to $60-80 \%$ during online 
learning as they could not comprehend the lesson well. This is very well supported in this study wherein the negative relationship was found with institutions support on their intentions with online learning as the switch to online mode was sudden. Due to this, the teachers and the institution might not have been able to prepare the class activities well to support the students with their learning. This result from this study is also very well supported in literature wherein it is mentioned that most of the students will not prefer to study online if there is an absence of interaction between lecturers and the students (Frankola 2001; Ibrahim et al. 2007) and hence it is essential for institutions to pay attention to effective instructional design if they want the students to study online in the future.

In the literature, PU impacted students' intentions as found by Huang et al. (2020); Amoako-Gyampah (2007) in their studies, but this study does not support that. The reason behind this different finding might be that the students in Vietnam are not familiar with online learning before the pandemic as this is a new learning mode and students are not much acquainted with this type of virtual learning. Thus, the students might not have been able to see as to how the usefulness of technology can impact their intention to use online learning in the future. The result from this study is evidenced by the BEAN survey conducted in Vietnam on university students wherein $46.2 \%$ of the surveyed respondents wanted to study on campus and not online class after COVID-19 is under control, while $35.3 \%$ of the students have shown interest towards blended learning and $4.6 \%$ of the students showed their preference for online learning (B and company 2020).

Most of the studies (Balog and Pribeanu 2010; Khalid 2014) done in the past supports that the perceived ease of use (PEU) and self-efficacy (SE) are significant factors impacting PE, but in this study, there was no impact found of intrinsic factors (PEU and SE) on perceived enjoyment. This result is not surprising as many students mentioned that they were not confident with online learning and were not sure whether online learning will be equally beneficial to them as compared to face to face learning (Nguyen and Pham 2020). Lastly, in this study, perceived enjoyment had a positive impact on students' intentions. This result is consistent with the past studies (Balog and Pribeanu 2010; Khalid 2014). The extrinsic factors had inversely affected PE and further PE had a direct effect on OLI. Although, extrinsic factors did not show the direct effect but there was an indirect effect of extrinsic factors on OLI. Hence, as a contribution to the ICT area, this research suggests new research variable related to extrinsic motivation which includes ICT infrastructure and internet access and speed, which influenced the students' OLI indirectly. With this added contribution of the variable from this study (which was not found in other studies to the best of the knowledge), this might provide completeness in the already existing research models and improve the existing theories and models from other studies. To summarize, this study results can add following contributions in the ICT area:

- A new research variable related to extrinsic motivation, which includes ICT infrastructure and internet access and speed (which was not found in other studies) can be added to the already existing research framework to measure the intentions of students (satisfaction) based on the results from this study.

- As most of the students are comfortable using the mobile phones, and hence mobile technology may be integrated further in the online learning. QR (Quick Response) 
codes can be used more often in the courses to provide the students the quick access to the related texts, audios, videos of various educational resources during online sessions and this might increase PE, which is one of the factors affecting OLI of students.

- Further, to provide a human touch, the lecturers can use videos, audios or instant messaging tools to reach out to the students or to provide them the feedback as PU was not found to be significant in this study and this might help further.

Although this study is specific to Vietnam, there are other geographic regions that are still experiencing a similar situation of shifting from traditional teaching to online teaching. Hence, this study results might be helpful in other parts of the world as well.

\section{Conclusion, limitations and implications}

Online learning is at an infancy stage in Vietnam. Many students find it difficult to learn in this learning environment due to different learning styles, lack of self-confidence, poor internet connectivity, under-developed instructional design and all these factors are impacting student learning intentions in the future. Vietnam is still using Industry 2.0 or 3.0 in education, while many countries are already using Industry 4.0 as per Vietnam Economic Times 2018. Hence based on the results of this study which shows that online learning might be impacted due to poor connectivity and slow connection, it is recommended to shift quickly to industry 4.0, even though Vietnam is making a push to embrace Industry 4.0 to make the learning environment effective with fast and better accessible internet.

Next recommendation might be useful for educational institutions based on the study results. The students felt that the instructional design was not effective and hence the class interaction might be missing, which affected students' online learning intentions negatively. To better support the students and the teachers, an official online learning and teaching training course can be developed along with using effective and user-friendly learning platforms. The students and teachers might have difficulty in switching the learning and teaching mode and hence in future to equip them well, the proper training is recommended. Also, one or two days in an academic year can be assigned explicitly to online learning to provide them the experience, so that it becomes easy to adapt with online learning in any difficult situations arising in the future.

COVID-19 pandemic might be an opportunity for educational institutions to review and strengthen their online learning and training capacity. There is a higher expansion in the higher education system in Vietnam, and educational industry will continue to boom in the coming decades. Hence, it is important for the institutions and the government to prepare themselves for any future uncertainties. Due to the slow development of online teaching, the higher education system in Vietnam has not developed enough compared to the country's economic development (Nguyen and Pham 2020). This pandemic might be a stepping-stone for Vietnam's digital transformation of the education system by permanently embedding this learning mode in their 
system. To embed online learning permanently into the system, this calls for improving every aspect right from infrastructure, curriculum design, teachers training to students training.

Embedding the online teaching and learning mode will need careful analysis of cost versus benefits. In regard to cost, first this will increase the cost of developing the sound online learning platform. Second, the cost will be involved in hiring the online specialists who can train the lecturers for using online platforms. Third, the resources will be required to develope the official online learning course for teachers and the students. There are several digital learning platforms which can be used by various institutions; such as Google Classrooms, Edmodo, Canvas, Moodle, Blackboard, Google Meet, Zoom, Microsoft Teams and many more and it is up to the universities to decide as which platform they would like to use to provide the best learning experience to the students in order to retain them in the future. In terms of benefits, any similar crisis might relieve the stress of the students, and the lectures and next online learning will prepare the independent learners for the future digital world. Online learning provides a lot of flexibility to the lecturers, and the students and if explored well, online learning can flourish more than the traditional learning in the future. Finally, during the post-graduation studies, many students might wish to work along with studying and the online learning gives them better flexibility in multitasking as this eliminates the learning place barrier. With online learning, the students also have the opportunity to re-watch the lecture recordings later to review the content. If universities see the advantages after doing cost-benefit analysis, then this COVID-19 outbreak should be the good starting point for reshaping learning and teaching. If universities are well prepared and if in future the switch from face-to-face to online learning platform is required, then it might be easy in any events of crisis and will also be helpful to meet the future demands.

The limitation of this study was that neither the teachers nor the students were trained to teach and study online as everything was sudden due to the pandemic, thus the results of this study might differ with similar kind of other studies done so far. Next limitation was the time constraint. Considering that the universities might not have been able to plan their online courses effectively, and this might have impacted the study results. Further, this study has only focused on university students', but the results might differ if school students are also included in the study. In future, the comparative study between the local and international universities might be conducted to see if there are any differences in students' intentions to online learning. Future stuides can also focus on the differences in enjoyment and learning intentions between students studying in universities and schools. Finally, cross-country studies in Asia might help to understand whether the learners' learning styles in different cultures can be one of the reason in their choice of learning mode.

\section{Abbreviations}

SEM, Structural Equation Model;

CFA, Confirmatory Factor Analysis;

ANOVA, Analysis of Variance; 
KMO, Kaiser-Meyer-Olkin test;

CFI, $\quad$ Comparative Fit Index;

AGFI, Adjusted goodness of fit;

GFI, Goodness of fit;

NFI, $\quad$ Normed fit index;

RMSEA, Root-mean-square error;

Cmin/df, Chi-square over the degree of freedom;

AVE, $\quad$ Average Variance Extracted;

COVID-19, Coronavirus Disease 2019;

IS ; $\quad$ Institutional Support;

SE, $\quad$ Self-Efficacy;

PEU, $\quad$ Perceived Ease of Use;

PU, $\quad$ Perceived Usefulness;

$O L I, \quad$ Online Learning Intentions;

PE, $\quad$ Perceived Enjoyment;

ICT, Information and Communication Technologies

\section{Appendix}

Table 6 Convergent validity and reliability results

\begin{tabular}{lll}
\hline Construct & AVE & $\begin{array}{l}\text { Construct Reliability } \\
\text { (Cronbach's alpha, } \alpha \text { ) }\end{array}$ \\
\hline Extrinsic Factors & 0.68 & 0.864 \\
Institutional Support & 0.7535 & 0.844 \\
Intrinsic Factors & 0.6085 & 0.859 \\
Perceived Enjoyment & 0.86 & 0.948 \\
Perceived Usefulness & 0.76 & 0.821 \\
Online Learning Intentions & 0.95 & 0.946 \\
\hline
\end{tabular}


Table 7 Factor Loadings

Extrinsic Factors

Infrastructure

Internet Resources

Institutional Support

Class Interaction

Teachers Support

Intrinsic Factors

Perceived Ease of Use (PEU)

Self-Efficacy (SE)

Perceived Enjoyment (Measure of Satisfaction)

PE1

PE2

PE3

PE4

PE5

PE6

Perceived Usefulness (PU)

PU1

PU2

PU3

Online Learning Intentions

OL1

\section{References}

A Train Education. (2020). COVID-19 Pandemic: A world in Turmoil. Retrieved from https://www.atrainceu. com/content/8-historical-context-sars-mers-and-ebola. Accessed 22 Oct 2020.

Akaike, H. (1987). Factor analysis and AIC. In Selected papers of hirotugu akaike (pp. 371-386). New York, NY: Springer.

Amoako-Gyampah, K. (2007). Perceived usefulness, user involvement and behavioral intention: An empirical study of ERP implementation. Computers in Human Behavior, 23(3), 1232-1248. https://doi.org/10. 1016/j.chb.2004.12.002.

Ayub, N. (2010). Effect of intrinsic and extrinsic motivation on academic performance. Pakistan Business Review, 8, 363-372.

B and Company. (2020). Retrieved from http://b-company.jp/en/online-education-en/. Accessed 17 Oct 2020.

Badri, M., Al Rashedi, A., Yang, G., Mohaidat, J., \& Al Hammadi, A. (2016). Students' intention to take online courses in high school: A structural equation model of causality and determinants. Education and Information Technologies, 21(2), 471-497. https://doi.org/10.1007/s10639-014-9334-8.

Balog, A., \& Pribeanu, C. (2010). The role of perceived enjoyment in the students' acceptance of an augmented reality teaching platform: A structural equation modelling approach. Studies in Informatics and Control, 19(3), 319-330. 
Baumgartner, H., \& Homburg, C. (1996). Applications of structural equation modeling in marketing and consumer research: A review. International Journal of Research in Marketing, 13(2), 139-161. https:// doi.org/10.1016/0167-8116(95)00038-0.

Bazelais, P., Doleck, T., \& Lemay, D. J. (2018). Investigating the predictive power of TAM: A case study of CEGEP students' intentions to use online learning technologies. Education and Information Technologies, 23(1), 93-111. https://doi.org/10.1007/s10639-017-9587-0.

Brinkerhoff, J. (2006). Effects of a long-duration, professional development academy on technology skills, computer self-efficacy, and technology integration beliefs and practices. Journal of Research on Technology in Education, 39(1), 22-43. https://doi.org/10.1080/15391523.2006.10782471.

Brown, J. D. (2002). The Cronbach alpha reliability estimate. JALT Testing \& Evaluation SIG Newsletter, $6(1), 17-18$.

Butler, D. L., \& Sellbom, M. (2002). Barriers to adopting technology. Educause Quarterly,

Byrne, B. (2013). Structural equation modeling with Mplus. In Structural Equation Modeling with Mplus. Routledge.

Cole, M. T., Shelley, D. J., \& Swartz, L. B. (2014). Online instruction, e-learning, and student satisfaction: A three year study. The International Review of Research in Open and Distributed Learning, 15(6). https:// doi.org/10.19173/irrodl.v15i6.1748.

Collins, M. (1999). I know my instructional technologies: it's these learners that perplex me! American Journal of Distance Education, 13(1), 8-23. https://doi.org/10.1080/08923649909527011.

Davis, F. D. (1989). Perceived usefulness, perceived ease of use, and user acceptance of information technology. MIS quarterly, 319-340.

Davis, F. D., Bagozzi, R. P., \& Warshaw, P. R. (1989). User acceptance of computer technology: A comparison of two theoretical models. Management Science, 35(8), 982-1003. https://doi.org/10.1287/ mnsc.35.8.982.

Davis, F. D., Bagozzi, R. P., \& Warshaw, P. R. (1992). Extrinsic and intrinsic motivation to use computers in the workplace 1. Journal of Applied Social Psychology, 22(14), 1111-1132. https://doi.org/10.2307/ 249008

Dinh, L. P., \& Nguyen, T. T. (2020). Pandemic, social distancing, and social work education: Students' satisfaction with online education in Vietnam. Social Work Education, 39(8), 1074-1083.

Doll, W. J., Xia, W., \& Torkzadeh, G. (1994). A confirmatory factor analysis of the end-user computing satisfaction instrument. MIS Quarterly, 18, 453-461. https://doi.org/10.2307/249524.

Esterhuyse, M., Scholtz, B., \& Venter, D. (2016). Intention to use and satisfaction of e-learning for training in the corporate context. Interdisciplinary Journal of Information, Knowledge, and Management, 11, 347365.

Eyitayo, O. (2011). Do students have the relevant ICT skills they need to do their research projects. Proceedings of the 2011 Conference on Information Technology Education, 287-292. https://doi.org/ $10.1145 / 2047594.2047668$.

Fassinger, P. A. (1995). Understanding classroom interaction: Students' and professors' contributions to students' silence. The Journal of Higher Education, 66(1), 82-96. https://doi.org/10.2307/2943952.

Frankola, K. (2001). Why online learners drop out. Workforce-Costa Mesa, 80(10), 52-61.

Galyon, C. E., Blondin, C. A., Yaw, J. S., Nalls, M. L., \& Williams, R. L. (2012). The relationship of academic self-efficacy to class participation and exam performance. Social Psychology of Education, 15(2), 233-249. https://oi.org/10.1007/s11218-011-9175-x.

Gore, P. A. Jr. (2006). Academic self-efficacy as a predictor of college outcomes: Two incremental validity studies. Journal of Career Assessment, 14(1), 92-115. https://doi.org/10.1177/1069072705281367.

Hooper, D., et al. (2008). Structural equation Modelling: Guidelines for determining model fit. The Electronic Journal of Business Research Methods, 6(1), 53-60.

Hsiao, E. L. (2012). Synchronous and asynchronous communication in an online environment: Faculty experiences and perceptions. Quarterly Review of Distance Education, 13(1), 15.

Hu, L. T., \& Bentler, P. M. (1999). Cutoff criteria for fit indexes in covariance structure analysis: Conventional criteria versus new alternatives. Structural Equation Modeling: A Multidisciplinary Journal, 6(1), 1-55. https://doi.org/10.1080/10705519909540118.

Huang, F., Teo, T., \& Zhou, M. (2020). Chinese students' intentions to use the internet-based technology for learning. Educational Technology Research and Development, 68(1), 575-591. https://doi.org/10.1007/ s11423-019-09695-y.

Hung, W. C., \& Jeng, I. (2013). Factors influencing future educational technologists' intentions to participate in online teaching. British Journal of Educational Technology, 44(2), 255-272. https://doi.org/10.1111/j. 1467-8535.2012.01294.x. 
Ibrahim, M., Rwegasira, K. S., \& Taher, A. (2007). Institutional factors affecting students' intentions to withdraw from distance learning programs in the Kingdom of Saudi Arabia the case of the Arab Open University (AOU). Online Journal of Distance Learning Administration, 10(1).

Irani, T. (2005). Communication potential, information richness and attitude: A study of computer mediated communication in the ALN classroom. Sloan-C. Retrieved March 11, 2007.

Junco, R., Elavsky, C. M., \& Heiberger, G. (2013). Putting twitter to the test: Assessing outcomes for student collaboration, engagement and success. British Journal of Educational Technology, 44(2), 273-287. https://doi.org/10.1111/j.1467-8535.2012.01284.x.

Khalid, N. (2014). The role of perceived usefulness and perceived enjoyment in assessing students' intention to use LMS using 3-tum. Proceedings of the Global Summit on Education GSE 2014.

Kuo, Y. C., Walker, A. E., Belland, B. R., \& Schroder, K. E. (2013). A predictive study of student satisfaction in online education programs. The International Review of Research in Open and Distance Learning, 14(1), 16-39.

Lee, J. W. (2010). Online support service quality, online learning acceptance, and student satisfaction. The Internet and Higher Education, 13(4), 277-283. https://doi.org/10.1016/j.iheduc.2010.08.002.

Lee, S. J., Srinivasan, S., Trail, T., Lewis, D., \& Lopez, S. (2011). Examining the relationship among student perception of support, course satisfaction, and learning outcomes in online learning. The Internet and Higher Education, 14(3), 158-163. https://doi.org/10.1016/j.iheduc.2011.04.001.

Lim, C. K. (2001). Computer self-efficacy, academic self-concept, and other predictors of satisfaction and future participation of adult distance learners. American Journal of Distance Education, 15(2), 41-51. https://doi.org/10.1080/08923640109527083.

Liu, I. F., Chen, M. C., Sun, Y. S., Wible, D., \& Kuo, C. H. (2010). Extending the TAM model to explore the factors that affect intention to use an online learning community. Computers \& Education, 54(2), 600610. https://doi.org/10.1016/j.compedu.2009.09.009.

Maheshwari, G., \& Thomas, S. (2017). An analysis of the effectiveness of the constructivist approach in teaching business statistics. Informing Science, 20, 83-97.

Meydan, C. H., \& Sesen, H. (2015). Yapisal esitlik modellemesi, Amos uygulamalari [Structural equation modeling, AMOS applications]. Ankara: Detay.

Moore, M. G. (1989). Editorial: Three types of interaction. American Journal of Distance Education, 3(2), 17. https://doi.org/10.1080/08923648909526659.

Mun, Y. Y., \& Hwang, Y. (2003). Predicting the use of web-based information systems: Self-efficacy, enjoyment, learning goal orientation, and the technology acceptance model. International Journal of Human-Computer Studies, 59(4), 431-449. https://doi.org/10.1016/S1071-5819(03)00114-9.

Nguyen, H. \& Pham, T. (2020). University World News. Retrieved from https://www.universityworldnews. com/post.php?story=20200512154252178. Accessed 17 Oct 2020.

Nichols, M. (2003). A theory for eLearning. Journal of Educational Technology \& Society, 6(2), 1-10.

Noora, A. (2008). Iranian undergraduates non-English majors' language learning preferences. GEMA Online ${ }^{\circledR}$ Journal of Language Studies, 8(2).

Oblinger, D., Oblinger, J. L., \& Lippincott, J. K. (2005). Educating the net generation. Brockport Bookshelf. 272. http://digitalcommons.brockport.edu/bookshelf/272.

Piper, D., \& Yan, W. (2001). The relationship between leadership, self-efficacy, computer experience, attitudes, and teachers' implementation of computers in the classroom. In J. Price, D. Willis, N. Davis \& J. Willis (Eds.), Proceedings of SITE 2001-Society for Information Technology \& Teacher Education International Conference (pp. 538-543). Norfolk, VA: Association for the Advancement of Computing in Education (AACE). Retrieved February 19, 2021 from https://www.learntechlib.org/primary/p/16751/.

Pollack, T., Thwaites G., \& Rabaa, M. (2020). EMERGING COVID-19 SUCCESS STORY: VIETNAM'S COMMITMENT TO CONTAINMENT. Retrieved from https://www.exemplars.health/emerging-topics/ epidemic-preparedness-and-response/covid-19/vietnam\#outbreak. Accessed 20 Oct 2020.

Quintana, S. M., \& Maxwell, S. E. (1999). Implications of recent developments in structural equation modeling for counseling psychology. The Counseling Psychologist, 27(4), 485-527. https://doi.org/10. $1177 / 0011000099274002$.

Shamburg, C. (2004). Conditions that inhibit the integration of technology for urban early childhood teachers. Information Technology in Childhood Education Annual, 2004(1), 227-244.

Shuey, S. (2002). Assessing online learning in higher education. Journal of Instruction Delivery Systems, $16(2), 13-18$.

Simpson, C., \& Du, Y. (2004). Effects of learning styles and class participation on students' enjoyment level in distributed learning environments. Journal of Education for Library and Information Science, 45(2), 123-136. https://doi.org/10.2307/40323899. 
Teo, T., \& Noyes, J. (2011). An assessment of the influence of perceived enjoyment and attitude on the intention to use technology among pre-service teachers: A structural equation modeling approach. Computers \& Education, 57(2), 1645-1653.

Thompson, B. (2004). Exploratory and confirmatory factor analysis. Washington, DC: American Psychological Association.

Vietnam Economic Times. (2018). Retrieved from https:/vneconomictimes.com/article/business/fount-ofknowledge-online. Accessed 17 Oct 2020.

Tung, F. C., \& Chang, S. C. (2007). Exploring adolescents' intentions regarding the online learning courses in Taiwan. Cyberpsychology \& Behavior, 10(5), 729-730.

Ullman, J. B., Tabachnick, B. G., \& Fidell, L. S. (2001). Using multivariate statistics. Structural Equation Modeling, 653-771.

Venkatesh, V., \& Morris, M. G. (2000). Why don't men ever stop to ask for directions? Gender, social influence, and their role in technology acceptance and usage behavior. MIS Quarterly, 24, 115-139. https://doi.org/10.2307/3250981.

Vonderwell, S. (2003). An examination of asynchronous communication experiences and perspectives of students in an online course: A case study. The Internet and Higher Education, 6(1), 77-90. https://doi. org/10.1016/S1096-7516(02)00164-1.

Wijekumar, K., Ferguson, L., \& Wagoner, D. (2006). Problems with assessment validity and reliability in web-based distance learning environments and solutions. Journal of Educational Multimedia and Hypermedia, 15(2), 199-215.

Woods, R. H. Jr. (2002). How much communication is enough in online courses? Eexploring the relationship between frequency of instructor-initiated personal email and learners' perceptions of and participation in online learning. International Journal of Instructional Media, 29(4), 377.

Yukselturk, E., \& Yildirim, Z. (2008). Investigation of interaction, online support, course structure and flexibility as the contributing factors to students' satisfaction in an online certificate program. Journal of Educational Technology \& Society, 11(4), 51-65.

Zhang, S., Zhao, J., \& Tan, W. (2008). Extending TAM for online learning systems: An intrinsic motivation perspective. Tsinghua Science and Technology, 13(3), 312-317.

Zimmerman, B. J. (2000). Self-efficacy: An essential motive to learn. Contemporary Educational Psychology, 25(1), 82-91. https://doi.org/10.1006/ceps.1999.1016.

Publisher's note Springer Nature remains neutral with regard to jurisdictional claims in published maps and institutional affiliations. 